\title{
EFFECT OF DENSITY REDUCTION ON UINTA GROUND SQUIRRELS: ANALYSIS OF LIFE TABLE RESPONSE EXPERIMENTS
}

\author{
Madan K. Oli, ${ }^{1,3}$ Norman A. Slade, ${ }^{2}$ and F. Stephen Dobson ${ }^{1}$ \\ ${ }^{1}$ Department of Biological Sciences, Auburn University, Auburn, Alabama 36849-5414 USA \\ ${ }^{2}$ Dyche Hall, Natural History Museum and Department of Ecology and Evolutionary Biology, University of Kansas, \\ Lawrence, Kansas 66045-7561 USA
}

\begin{abstract}
The effects of natural or experimental environmental perturbations on populations can be diverse, simultaneously affecting several life history variables. Populationlevel responses to such influences frequently are measured as changes in projected population growth rate $(\lambda)$. Sensitivity and elasticity analyses can be used to quantify the potential influence of small changes in different life history variables on $\lambda$. When a population is subjected to an experimental treatment, life table response experiment (LTRE) analysis allows decomposition of changes in $\lambda$ into contributions due to observed changes in individual life history variables. We investigated the potential and actual influence of demographic characteristics (age at maturity, juvenile and adult survival, fertility, and age at last reproduction) on $\lambda$ of Uinta ground squirrels (Spermophilus armatus) in the Wasatch Mountains of Utah, USA. Ground squirrels were studied in three different habitats, before and after an experimental reduction of population size. Survival and reproduction of squirrels increased in response to a reduction in population density. Consequently, $\lambda$ increased by at least $21 \%$ in two of the three habitats. Population growth rate was potentially most sensitive to changes in age at maturity $(\alpha)$ and fertility. LTRE analysis revealed that $\alpha$ did not change and contributed nothing to changes in $\lambda$, but changes in fertility were large and contributed most to observed changes in $\lambda$. Age at last reproduction $(\omega)$ increased after density reduction but contributed little to observed changes in $\lambda$ because of low sensitivity of $\lambda$ to changes in $\omega$. Thus, there was little correspondence between potential influence and actual contributions to observed changes in $\lambda$. We concluded that some demographic variables, notably $\alpha$, had little environmental or phylogenetic scope for reduction, whereas fertility and to some degree survival rates were considerably more plastic under the experimental treatment. Because LTRE analysis incorporates observed changes in life history variables and also sensitivity of $\lambda$ to these changes, it worked well for quantifying the response of Uinta ground squirrel populations to density manipulation and holds promise for evaluating alternative management strategies in conservation biology.
\end{abstract}

Key words: age-structured models; decomposition of treatment effect; density reduction; elasticity; life table response experiment; LTRE analysis; matrix population models; partial life cycle models; sensitivity analysis; Spermophilus armatus; Uinta ground squirrels; Utah (USA).

\section{INTRODUCTION}

It is a fundamental principle of population ecology that when demographic variables change in response to environmental perturbations, population growth rate $(\lambda)$ is likely to change as well. Population biologists seek to quantify the potential influence of life history variables on population growth rate and to determine the response of $\lambda$ to actual changes in life history variables (Horvitz et al. 1997). Evaluating the influence on $\lambda$ of changes in life history variables, however, can be difficult. For example, the demographic changes underlying multiannual population cycles of voles and lemmings have proven elusive (Krebs 1996, Tkadlec

Manuscript received 3 April 2000; revised and accepted 3 August 2000.

${ }^{3}$ Present address: Department of Wildlife Ecology and Conservation, 303 Newins-Ziegler Hall, University of Florida, Gainesville, Florida 32611 USA.

E-mail: olim@wec.ufl.edu and Zejda 1998). When demographic influences were treated as alternative hypotheses in a simulation study, the age at which females begin to reproduce and juvenile survival were implicated as potentially key demographic elements of the cycles (Oli and Dobson 1999).

Influences of demographic variables on changes in $\lambda$ can be examined using two approaches: prospective and retrospective (Horvitz et al. 1997, Caswell 2000). The prospective approach examines the sensitivity of $\lambda$ to changes in underlying demographic variables. Sensitivity analyses quantify the potential influence on $\lambda$ of small absolute (sensitivity) or proportional (elasticity) changes in demographic variables (e.g., Caswell 1989b, 1997, Horvitz et al. 1997, de Kroon et al. 2000, Heppell et al. 2000a). Prospective analyses deal with hypothetical situations (e.g., "if each demographic variable were to change by $5 \%$, which variable would cause largest change in $\lambda$ ?"). 
In contrast, retrospective analyses deal with natural or experimental perturbations to the environment that have engendered changes in life history variables, causing $\lambda$ to change. The focus of retrospective analyses, such as analyses of life table response experiments (LTRE), is to decompose the population-level response into contributions from individual demographic variables (Caswell 1989a, Levin et al. 1996, Horvitz et al. 1997). While sensitivity analyses indicate the potential influence on $\lambda$ of changes in demographic variables, genetic or environmental circumstances may limit changes in some demographic characteristics. For example, age at maturity $(\alpha)$ has been suggested to be a potentially influential demographic variable (Cole 1954, Lewontin 1965). However, $\alpha$ in some species inhabiting highly seasonal temperate and arctic environments shows little or no change even under experimental perturbations in the environment (e.g., Dobson 1988, Dobson and Michener 1995, Jouventin et al. 1999). Conversely, survival and fertility rates may be extremely labile from habitat to habitat or year to year (e.g., Slade and Balph 1974, Dobson and Murie 1987, Dobson 1988). LTRE analysis combines sensitivity of $\lambda$ to life history variables with observed demographic changes and thus quantifies the actual influence of demographic variables when population growth rate changes over time or space (Caswell 1989a, b, 2000, Levin et al. 1996, Horvitz et al. 1997, Ehrlèn and van Groenendael 1998).

LTRE analyses can be used to explore natural changes in $\lambda$ over time or space and to examine responses to experimental manipulations. Such experiments may involve manipulations that artificially cause changes in population growth rate, such as food supplementation (e.g., Cole and Batzli 1978, Jansson et al. 1981, Dobson 1988, 1995, Guyer 1988, Boutin 1990), decrementing population size (e.g., Slade and Balph 1974, Arcese and Smith 1988), manipulation of predators (e.g., Marcström et al. 1988, Krebs et al. 1995), exposure to pollutants (e.g., Levin et al. 1996), or a combination of several factors (e.g., Birch 1953, Taitt and Krebs 1983, Rao and Sharma 1986, Krebs et al. 1995). The majority of such studies, particularly those of terrestrial vertebrates, have not applied LTRE analyses (but see Brault and Caswell 1993), although several have documented changes in demographic variables that could cause changes in population growth rate.

The purpose of our study was to apply LTRE analysis in a reexamination of an experimental reduction in population density that was applied to Uinta ground squirrels (Spermophilus armatus) by Slade and Balph (1974). This species was particularly appropriate for our study, not only because of the experimental treatment, but also because habitat- and age-specific life table data were gathered. Using LTRE analyses, we examined the contribution of demographic variables to observed changes in $\lambda$ under the experimental treatment in three different habitats. A second purpose was to investigate if demographic variables that showed large responses to density reduction or those with high elasticities actually made large contributions to observed changes in $\lambda$ as revealed by LTRE analyses.

\section{Materials And Methods \\ Study area and field methods}

We analyzed data from Uinta ground squirrels (Spermophilus armatus) occupying three different types of habitat (lawn, nonlawn, and edge habitats) at the Utah State University Forestry Station, Wasatch Mountains, $35 \mathrm{~km}$ northeast of Logan, Utah, USA. During the first phase of the study (1964-1968), squirrels were captured and marked at emergence from hibernation. Virtually all squirrels in each habitat were captured, marked, and followed until disappearance from the study area. Originally, a life table was constructed for the female segment of the population in each habitat (Slade and Balph 1974; hereafter "pre-reduction life tables"). During the second phase of the study (19681970 ), population density in each habitat was reduced by $\sim 60 \%$ using a stratified random sampling protocol such that sex and age composition remained unchanged. Life tables were constructed for female squirrels in each habitat following density reduction (Slade and Balph 1974; hereafter "post-reduction life tables"). We therefore had three pre-reduction life tables and three post-reduction life tables. A detailed description of the study area, field methods, and population biology of Uinta ground squirrels is given in Slade and Balph (1974).

\section{Demographic analyses}

We estimated annual age-specific survival probabilities $\left(P_{i}\right)$ and fertilities $\left(F_{i}\right.$; sensu Caswell 1989b) using the birth-pulse, post-breeding census formulation of Caswell (1989b):

$$
\begin{gathered}
P_{i}=\frac{l_{i}}{l_{i-1}} \\
F_{i}=P_{i} m_{i}
\end{gathered}
$$

where $l_{i}$ is the survivorship (probability at emergence from natal burrows of surviving to age $i$ ), and $m_{i}$ is the fecundity (the average number of daughters born to females of age $i$ ). An age-classified Leslie matrix $\mathbf{A}$ was constructed for each combination of habitat (lawn, nonlawn, and edge) and treatment (pre- and post-density reduction; Table 1$)$. Population growth rate $(\lambda)$ was calculated as the dominant eigenvalue of each matrix. The sensitivity $\left(\partial \lambda / \partial a_{i j}\right)$ and elasticity $\left(e_{i j}\right)$ of $\lambda$ to changes in the $i j$ th entry of the transition matrix were calculated as

$$
\begin{aligned}
\frac{\partial \lambda}{\partial a_{i j}} & =\frac{v_{i} w_{j}}{\langle\mathbf{w}, \mathbf{v}\rangle} \\
e_{i j} & =\frac{\partial \lambda}{\partial a_{i j}} \frac{a_{i j}}{\lambda}
\end{aligned}
$$


TABle 1. Age-specific fertility $\left(F_{i}\right)$ and annual survival rates $\left(P_{i}\right)$ of Uinta ground squirrels for each habitat (lawn, nonlawn, and edge) and treatment (pre- and post-density reduction) combination at the Utah State University Forestry Station, Wasatch Mountains, Utah, USA.

\begin{tabular}{|c|c|c|c|c|c|c|}
\hline \multirow[b]{2}{*}{ Habitat/treatment } & \multicolumn{3}{|c|}{ Survival } & \multicolumn{3}{|c|}{ Fertility } \\
\hline & $\begin{array}{l}\text { Young of } \\
\text { the year }\end{array}$ & Yearling & Adult & $\begin{array}{l}\text { Young of } \\
\text { the year }\end{array}$ & Yearling & Adult \\
\hline \multicolumn{7}{|l|}{ Lawn } \\
\hline Pre-reduction & 0.292 & 0.438 & 0.320 & 0.572 & 1.197 & 0.870 \\
\hline Post-reduction & 0.359 & 0.529 & 0.468 & 0.628 & 1.461 & 1.293 \\
\hline \multicolumn{7}{|l|}{ Nonlawn } \\
\hline Pre-reduction & 0.375 & 0.419 & 0.500 & 0.353 & 0.741 & 0.885 \\
\hline Post-reduction & 0.474 & 0.481 & 0.588 & 0.792 & 0.981 & 1.200 \\
\hline \multicolumn{7}{|l|}{ Edge } \\
\hline Pre-reduction & 0.350 & 0.440 & 0.429 & 0.445 & 0.845 & 0.823 \\
\hline Post-reduction & 0.167 & 1.000 & 0.497 & 0.334 & 1.880 & 0.934 \\
\hline
\end{tabular}

Notes: Survival and fertility rates are given for young of the year (emergence to $1 \mathrm{yr}$ of age), yearling (1-2 yr of age), and adult ( $>2 \mathrm{yr}$ of age) squirrels; demographic rates are equal for all adult age classes $(>2 \mathrm{yr})$. Ages at first $(\alpha)$ and last ( $\omega)$ reproduction are given in Table 3.

(Caswell 1989b, 1997, de Kroon et al. 2000), where w and $\mathbf{v}$ are the right and left eigenvectors, respectively, of matrix A corresponding to the dominant eigenvalue, $\lambda$, and $\langle\mathbf{w}, \mathbf{v}\rangle$ is the scalar product of $\mathbf{w}$ and $\mathbf{v}$. Elasticities are scaled, dimensionless quantities and are thus directly comparable among demographic variables and across populations (Caswell et al. 1984, de Kroon et al. 1986, 2000, Caswell 1989b, Horvitz et al. 1997). Therefore, we used elasticities to quantify the potential influence of demographic variables on $\lambda$.

The original data used in Slade and Balph (1974) were not available so we could not employ resampling methods (Lenski and Service 1982, Caswell 1989b, McPeek and Kalisz 1993) for statistical inference regarding changes in $\lambda$ 's in response to experimental treatment. Instead, we calculated crude estimates of variation in $\lambda$ by assuming that each element in the Leslie matrix was an independent random variable. We estimated the variance of the survival rates, $P_{i}$, with the standard formula for the estimate of a binomial parameter: $\operatorname{var}\left(\hat{p}_{i}\right)=\hat{p}_{i}\left(1-\hat{p}_{i}\right) / n$. To estimate the variance of fertilities, $F_{i}$, we estimated separate fertility terms for each year and then calculated sample variance in these terms among years. The variance of $\lambda$ was then calculated using the formula in Caswell $(1989 b: 185)$ as products of squared sensitivities and estimated variances summed over all nonzero elements of the Leslie matrix.

We used the transition matrix constructed from the pre-reduction life table as a reference for each habitat to evaluate the effect of density reduction on each population of Uinta ground squirrels. Change in a demographic rate $a_{i j}$ in response to density reduction was calculated as: $\Delta a_{i j}=a_{i j}^{\text {post }}-a_{i j}^{\text {pre }}$. Total change in $\lambda$ in response to density reduction, i.e., the effect of density reduction on the entire life table, was calculated as: $\Delta \lambda$ $=\lambda^{\text {post }}-\lambda^{\text {pre }}$. We decomposed $\Delta \lambda$ into contributions from age-specific demographic rates following Caswell $(1989 a, b)$ :

$$
\left.\Delta \lambda \approx \sum_{i j} \Delta a_{i j} \frac{\partial \lambda}{\partial a_{i j}}\right|_{\left[\left(\mathrm{A}^{\mathrm{post}}+\mathrm{A}^{\mathrm{pre}}\right) / 2\right]}
$$

where $\Delta a_{i j} \partial \lambda / \partial a_{i j}$ represents the LTRE contribution of $\Delta a_{i j}$ to total change in $\lambda(\Delta \lambda)$ in response to density reduction.

Although Leslie matrix models incorporate age-specific demographic data, life history variables such as $\alpha$ and age at last reproduction $(\omega)$ do not appear explicitly in these models. Consequently, the contribution of $\alpha$ and $\omega$ in an LTRE cannot be calculated using standard techniques. Therefore, we used a partial life cycle model for this purpose (Caswell 1989b, Levin et al. 1996, Oli 1999, Oli and Zinner, 2001). In a partial life cycle model, age-specific fertilities $F_{i}$ are approximated by age-independent fertility rate $\bar{F}$, age-specific survival $P_{i}$ prior to reproduction (i.e., juvenile survival) by $P_{\mathrm{j}}$, and age-specific survival from $\alpha$ until $\omega$ by $P_{\mathrm{a}}$ (Fig. 1). The characteristic equation for this type of two-stage life cycle is

$$
\begin{aligned}
1= & \bar{F} P_{\mathrm{j}}^{\alpha-1} \lambda^{-\alpha}-\bar{F} P_{\mathrm{j}}^{\alpha-1} P_{\mathrm{a}} \lambda^{-\alpha-1}+\bar{F} P_{\mathrm{j}}^{\alpha} \lambda^{-\alpha-1} \\
& -\bar{F} P_{\mathrm{j}}^{\alpha} P_{\mathrm{a}}^{\omega-\alpha} \lambda^{-\omega-1}+P_{\mathrm{a}} \lambda^{-1} .
\end{aligned}
$$

(Oli 1999, Oli and Zinner, 2001; see Levin et al. [1996] for a similar model).

The $\lambda$ is the largest real root of Eq. 6 and can be obtained numerically. For the partial life cycle model, $\alpha$ and $\omega$ were the first and last age classes with nonzero fertility, respectively. To ensure maximum correspondence between results of age-classified and partial life cycle models, $\bar{F}$ and $P_{\text {a }}$ were estimated from the ageclassified transition matrix as weighted averages, weighted according to the contribution of each age 


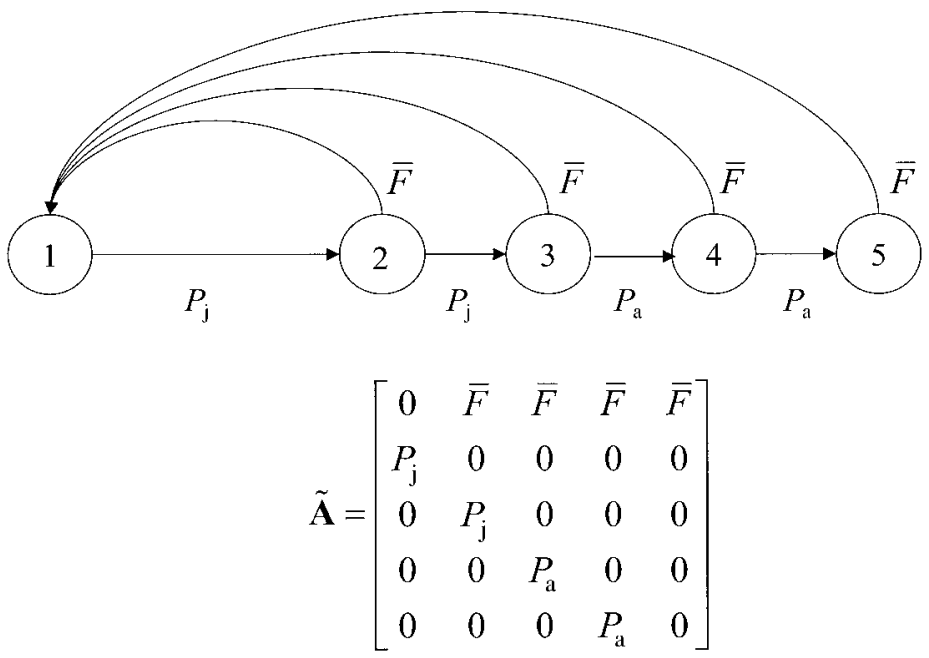

FIG. 1. A partial life cycle graph for age at maturity $(\alpha)=2$ and age at last reproduction $(\omega)=5$. Data are assumed to be collected from post-breeding censuses. In a partial life cycle graph, age-specific fertilities $\left(F_{i}\right)$ are estimated by an age-independent fertility parameter $\bar{F}$, age-specific survival probabilities until first reproductive event by a juvenile survival parameter $P_{\mathrm{j}}$, and age-specific survival probabilities thereafter by an adult survival parameter $P_{\mathrm{a}}$. A projection matrix $\tilde{\mathbf{A}}$ corresponding to the partial life cycle graph is also given (Oli and Zinner 2001). class to the stable age distribution (Oli 1999, Oli and Zinner, 2001):

$$
\begin{gathered}
\bar{F}=\frac{\sum_{i=\alpha}^{\omega} \mathbf{w}_{i} F_{i}}{\sum_{i=\alpha}^{\omega} \mathbf{w}_{i}} \\
P_{a}=\frac{\sum_{i=\alpha+1}^{\omega-1} \mathbf{w}_{i} P_{i}}{\sum_{i=\alpha+1}^{\omega-1} \mathbf{w}_{i}}
\end{gathered}
$$

where $\mathbf{w}_{i}$ is the $i$ th entry of the right eigenvector corresponding to the dominant eigenvalue of the age-classified transition matrix $\mathbf{A}$.

The sensitivity of $\lambda$ to changes in a model parameter $p$ is the partial derivative of $\lambda$ with respect to $p$ (i.e.,

TABle 2. Population growth rate $(\lambda \pm 1 \mathrm{SE})$ and change in population growth rate $(\Delta \lambda)$ in response to density reduction for each habitat (lawn, nonlawn, and edge) and treatment (pre- and post-density reduction) combination.

\begin{tabular}{lcc}
\hline \hline & \multicolumn{2}{c}{$\lambda$} \\
\cline { 2 - 3 } Habitat/treatment & Leslie matrix & $\begin{array}{c}\text { Partial life } \\
\text { cycle model }\end{array}$ \\
\hline Lawn & \\
Pre-reduction & $1.048 \pm 0.153$ & 1.040 \\
Post-reduction & $1.274 \pm 0.181$ & 1.274 \\
$\Delta \lambda$ & 0.226 & 0.234 \\
Nonlawn & & \\
Pre-reduction & $0.948 \pm 0.121$ & 0.949 \\
Post-reduction & $1.377 \pm 0.206$ & 1.378 \\
$\Delta \lambda$ & 0.429 & 0.429 \\
Edge & & \\
Pre-reduction & $0.970 \pm 0.097$ & 0.970 \\
Post-reduction & $0.972 \pm 0.313$ & 0.958 \\
$\Delta \lambda$ & 0.002 & -0.012 \\
\hline
\end{tabular}

Notes: Population growth rate was calculated using the Leslie matrix and partial life cycle models. $\partial \lambda / \partial p$, where $p$ is $\alpha, \omega, P_{\mathrm{j}}, P_{\mathrm{a}}$, or $\bar{F}$ ) and can be obtained by implicit differentiation of Eq. 6 (Oli and Zinner $2001)$. The elasticity or proportional sensitivity of $\lambda$ to changes in $p$ was calculated as $\partial \lambda / \partial p p / \lambda$ (Caswell et al. 1984, de Kroon et al. 1986, 2000, Caswell 1989b, Oli and Zinner 2001). By analogy to Eq. 5, total change in $\lambda$ in response to density reduction was decomposed (an LTRE analysis) into contributions from changes in a model parameter $p$ (Levin et al. 1996):

$$
\left.\Delta \lambda \approx \sum_{i j} \Delta p \frac{\partial \lambda}{\partial p}\right|_{\left[\left(p^{\mathrm{post}}+p^{\mathrm{pre}}\right) / 2\right]}
$$

where $\Delta \lambda$ is the total change in $\lambda$ in response to density reduction, and $\Delta p$ is the change in a model parameter $p\left(\alpha, \omega, P_{\mathrm{j}}, P_{\mathrm{a}}\right.$, or $\left.\bar{F}\right)$ in response to density reduction. Sensitivities are evaluated at the mean of the pre- and post-density reduction parameter values (Caswell 1989a, b, Levin et al. 1996).

\section{RESULTS}

\section{Population growth rate}

Ground squirrels that occupied different habitat types differed demographically (Table 1). Changes following the density reduction treatment were often greater than differences among habitat types, however. Survival and fertility of ground squirrels were generally increased by the density reduction, with the exception that survival and fertility of young of the year decreased in the edge habitat. Density reduction produced substantial increases in $\lambda$, of $\sim 22 \%$ and $43 \%$ in lawn and nonlawn habitats, respectively. Population growth rates calculated using the partial life cycle model closely resembled those obtained from the corresponding age-classified matrix models, suggesting that the partial life cycle model was an adequate proxy for the age-classified Leslie matrix model (Table 2). 

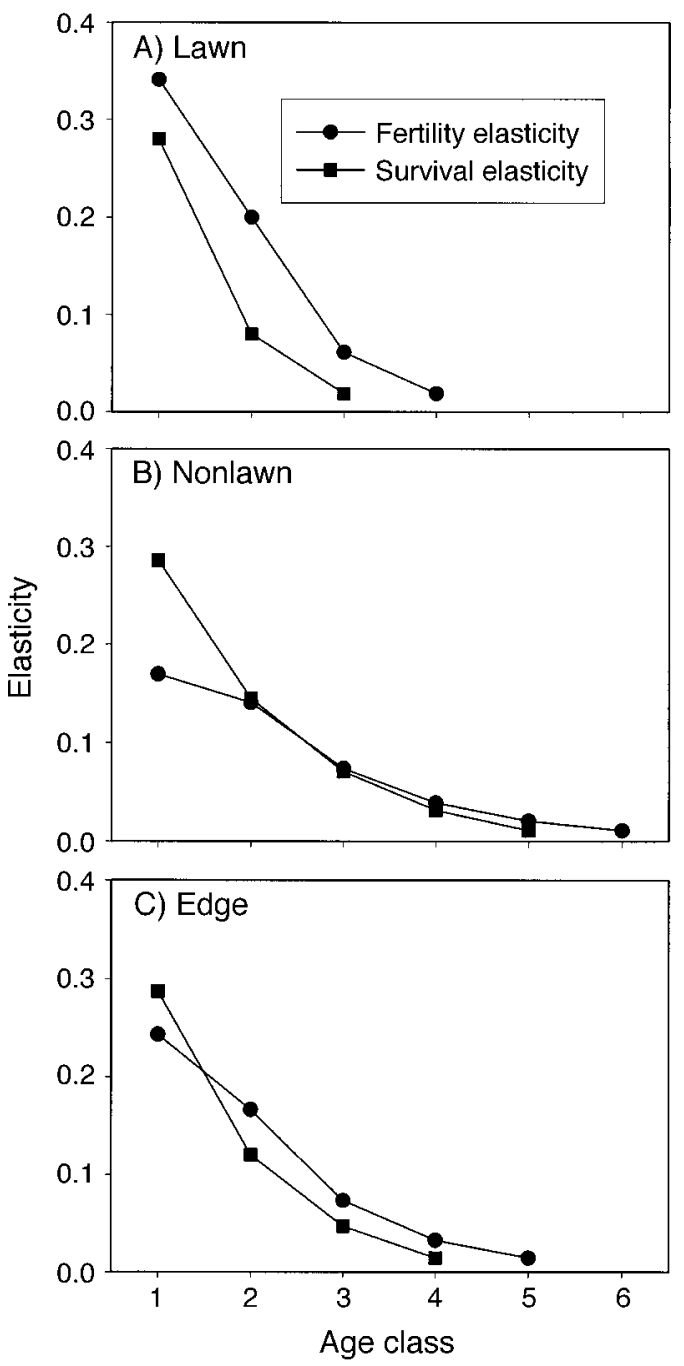

FIG. 2. Elasticity (proportional sensitivity) of population growth rate to changes in age-specific fertility and survival probabilities of Uinta ground squirrels in (A) lawn, (B) nonlawn, and (C) edge habitats. Elasticities for all habitats were calculated from an age-classified Leslie matrix parameterized with pre-reduction life tables.

\section{Elasticities and decomposition of treatment effects: age-classified model}

Elasticities of age-specific survival probabilities $\left(P_{i}\right)$ and fertilities $\left(F_{i}\right)$ were higher for younger age classes and declined monotonically for older age classes (Fig. 2). Survival probability and fertility for the first age class had the highest elasticities in all three habitats. The influence of density reduction on age-specific fertilities and survival probabilities was generally positive, except for $F_{1}$ and $P_{1}$ in edge habitat (Fig. 3). Responses of $F_{i}$ and $P_{i}$ to density reduction differed among age classes. Age-specific demographic rates that changed most at reduced density were: fertility and survival rate for age class 6 in lawn habitat, fertility and survival rate for age class 7 in nonlawn habitat, and fertility and survival rate for age class 2 in edge habitat (Fig. 3).

LTRE analysis revealed that increases in $\lambda$ were due primarily to increases in survival and fertility in the first two age classes (Fig. 4), except in the edge habitat. In the edge habitat, the influence on $\lambda$ of decreased fertility and survival rate for the first age class was balanced by contributions due to increases in survival and fertility in older age classes; consequently, $\lambda$ remained unchanged.

\section{Elasticities and LTRE contributions: partial life cycle model}

In lawn and edge habitats, $\alpha$ and $F$ had the largest and second largest elasticities, respectively; the pattern was reversed in nonlawn habitat. In all habitats, elasticity of $P_{\mathrm{j}}$ exceeded that of $P_{\mathrm{a}}$. Elasticities of $\omega$ were
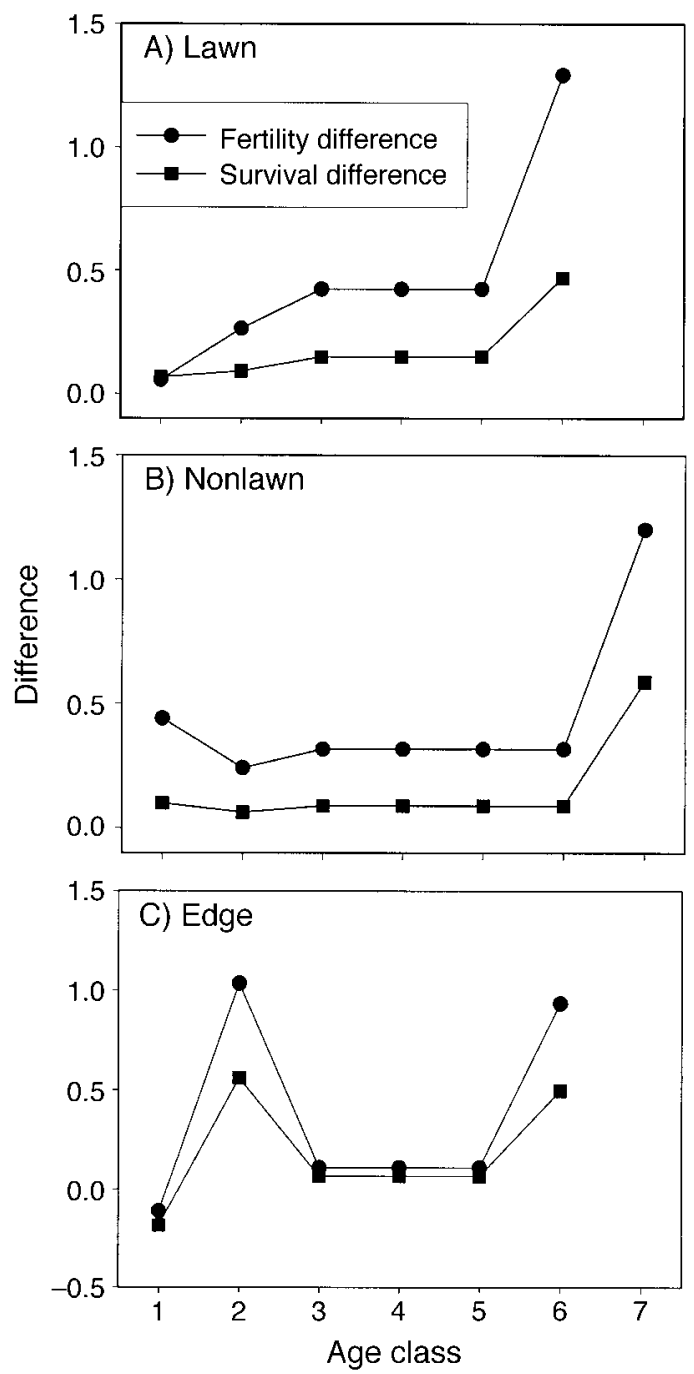

FIG. 3. Changes in age-specific fertilities and survival rates of Uinta ground squirrels in response to density reduction in (A) lawn, (B) nonlawn, and (C) edge habitats. 

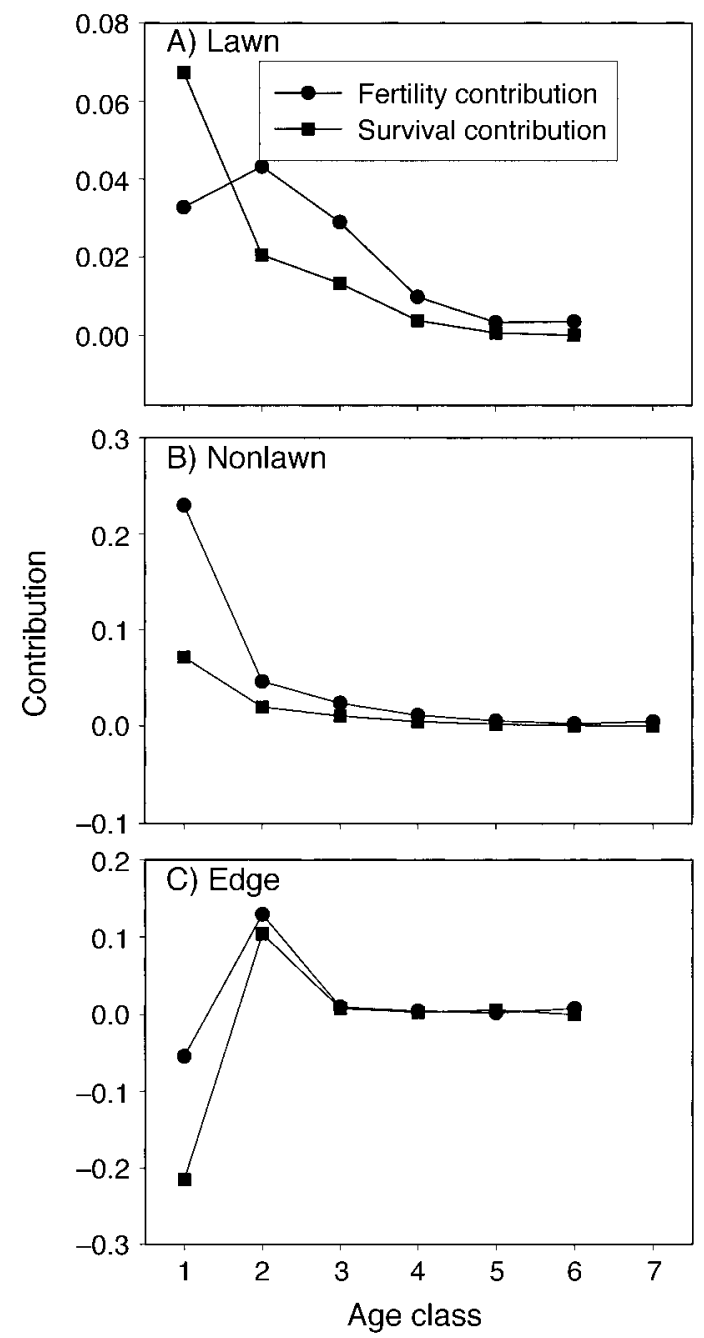

FIG. 4. Life table response experiment (LTRE) contributions of age-specific fertilities and survival rates of Uinta ground squirrels to observed changes in population growth rate in: (A) lawn, (B) nonlawn, and (C) edge habitats. Note the differences in scale for the contributions among sites.

low for all habitats, indicating that increased longevity would contribute little to changes in $\lambda$ (Table 3 ).

Density reduction generally increased survival and fertility in the partial life cycle model to varying degrees, except for the decreases in juvenile survival in edge habitat. The $\alpha$ remained unchanged, but $\omega$ increased by at least $1 \mathrm{yr}$ in all habitats (Table 3 ). Thus, $\alpha$ was potentially influential but did not change, whereas $\omega$ was relatively unimportant but did increase in response to density reduction.

LTRE analyses revealed that changes in fertility made the highest contribution to the observed changes in $\lambda$ in response to density reduction in lawn and nonlawn habitat, but the negative contribution of juvenile survival exceeded the contribution of any other variable in edge habitat. As with the age-classified models, life history variables that had the highest elasticities or those most affected by the treatment did not always make the highest LTRE contributions (Table 3). The sum of LTRE contributions (Table 3) matched the observed changes in $\lambda$ (Table 2), suggesting adequacy of the LTRE model.

\section{Discussion}

In lawn and nonlawn habitats, survival and reproduction increased at low density; consequently, $\lambda$ increased by at least $21 \%$ in these two habitats (Tables 1 and 2). In the edge habitat, reproduction and adult survival increased, but these changes were balanced by an overall decline in juvenile survival; consequently, $\lambda$ remained essentially unchanged. We lacked adequate data to apply resampling techniques and thus could not statistically test the significance of changes in $\lambda$ in response to density reduction. However, approximate standard errors of $\lambda$ 's (Table 2) indicate that observed changes in $\lambda$ in lawn and nonlawn habitats were real. The lack of a population-level response to density reduction in edge habitat may have been due to sampling error or poor habitat quality (Slade and Balph 1974). Population growth rates calculated from the two models were similar, suggesting that the partial life cycle model served as a good proxy for the age-classified Leslie matrix model. Because variables such as $\alpha$ and $\omega$ appear explicitly as model parameters, a partial life cycle model (Caswell 1989b, Levin et al. 1996, Oli 1999, Oli and Zinner 2001) is preferable to age-classified models when sensitivity or LTRE analyses involving these demographic variables are of interest.

Given that Uinta ground squirrels exhibited substantial population-level responses to density reduction, our purpose was to examine potential and actual influences of demographic variables on $\lambda$. Potential influences can be evaluated through examination of elasticities (or proportional sensitivities) of $\lambda$ to demographic variables (Caswell 1989b, Levin et al. 1996, Horvitz et al. 1997). The use of elasticities as potential influences of demographic variables on population growth is reasonable, given the substantial changes in demography that can occur under experimentally induced changes in population growth rate (Boutin 1990). All of the demographic variables that we examined have been found to be phenotypically plastic under experimental conditions in other ground squirrel species (Dobson and Murie 1987, Dobson 1988).

Elasticity of $\lambda$ to changes in $\alpha$ of Uinta ground squirrels were high for all three habitats, indicating a major potential influence of $\alpha$ on $\lambda$ (Table 3). However, LTRE analyses revealed that $\alpha$ contributed nothing to observed changes in $\lambda$ because this variable could not respond to density manipulations. This occurred because most yearling female ground squirrels breed shortly after they emerge from a winter-long hibernation period. Under the experimental treatment, $\alpha$ could only improve if females bred in their first active season, before hibernation. In the mountain environment of 
TABLE 3. Sensitivities of population growth rate and life table response experiment (LTRE) contributions of model parameters calculated using the partial life cycle model. Pre- and post-density reduction parameter values and changes in model parameters in response to density reduction $(\Delta p)$ are also given.

\begin{tabular}{|c|c|c|c|c|c|c|}
\hline \multirow[b]{2}{*}{ Parameter } & \multicolumn{2}{|c|}{ Parameter value } & \multirow[b]{2}{*}{$\Delta p$} & \multirow[b]{2}{*}{ Elasticity $\dagger$} & \multirow[b]{2}{*}{ Sensitivity $\ddagger$} & \multirow{2}{*}{$\begin{array}{c}\text { LTRE } \\
\text { contribution }\end{array}$} \\
\hline & Pre & Post & & & & \\
\hline \multicolumn{7}{|l|}{ Lawn } \\
\hline$\alpha$ & 1.000 & 1.000 & 0.000 & -0.896 & -0.998 & 0.000 \\
\hline$\omega$ & 4.000 & 6.000 & 2.000 & 0.049 & 0.006 & 0.012 \\
\hline$P_{\mathrm{j}}$ & 0.292 & 0.359 & 0.067 & 0.210 & 0.747 & 0.050 \\
\hline$P_{-\mathrm{a}}^{\mathrm{J}}$ & 0.403 & 0.506 & 0.103 & 0.094 & 0.294 & 0.030 \\
\hline $\bar{F}^{\mathrm{a}}$ & 0.726 & 0.871 & 0.145 & 0.696 & 0.980 & 0.142 \\
\hline \multicolumn{7}{|l|}{ Nonlawn } \\
\hline$\alpha$ & 1.000 & 1.000 & 0.000 & -0.532 & -0.716 & 0.000 \\
\hline$\omega$ & 6.000 & 7.000 & 1.000 & 0.028 & 0.002 & 0.002 \\
\hline$P_{\mathrm{j}}$ & 0.375 & 0.474 & 0.099 & 0.241 & 0.640 & 0.063 \\
\hline$P_{\mathrm{a}}^{\mathrm{J}}$ & 0.455 & 0.521 & 0.066 & 0.191 & 0.376 & 0.025 \\
\hline $\bar{F}^{a}$ & 0.546 & 0.888 & 0.342 & 0.568 & 0.988 & 0.338 \\
\hline \multicolumn{7}{|l|}{ Edge } \\
\hline$\alpha$ & 1.000 & 1.000 & 0.000 & -0.631 & -0.767 & 0.000 \\
\hline$\omega$ & 5.000 & 6.000 & 1.000 & 0.040 & 0.010 & 0.010 \\
\hline$P_{\mathrm{j}}$ & 0.350 & 0.167 & -0.183 & 0.236 & 0.802 & -0.147 \\
\hline$P_{\mathrm{a}}^{\mathrm{J}}$ & 0.436 & 0.675 & 0.239 & 0.152 & 0.350 & 0.084 \\
\hline $\bar{F}^{a}$ & 0.596 & 0.644 & 0.048 & 0.612 & 0.922 & 0.044 \\
\hline
\end{tabular}

Notes: Demographic variables are: $\alpha=$ age at maturity, $\omega=$ age at last reproduction, $P_{\mathrm{j}}=$ juvenile survival, $P_{\mathrm{a}}=$ adult survival, and $\bar{F}=$ fertility rate.

$\dagger$ Elasticities were calculated for pre-density reduction parameter values.

\$ Sensitivities were evaluated at the mean (of pre- and post-density reduction) values of model parameters.

these ground squirrels, young must be produced early enough in the growing season for growth, fattening, and a subsequent hibernation season of $\sim 8$ mo (Knopf and Balph 1977). Therefore, $\alpha$ in our study populations was already at minimum before the density reduction treatment, and further improvements in this variable were not possible; these observations suggest that demographic traits such as $\alpha$ may be phylogenetically or environmentally constrained in some populations. In both lawn and nonlawn habitats, where $\lambda$ increased substantially in response to density reduction, fertility contributed most to observed changes in $\lambda$, followed by juvenile survival rates. The lack of correspondence between the relative magnitude of LTRE contributions and changes in demographic variables in response to density reduction (Table 3 ) further corroborates Caswell's (1989a) proposition that large changes in demographic variables may not translate into large contributions to observed changes in $\lambda$.

Some fundamental principles of population ecology were confirmed by our study. As the ground squirrels aged, there was a general decline in the potential influence of survival and reproduction on population growth (Fig. 2). This result is virtually guaranteed by the demography of the ground squirrels. As the population ages, fewer and fewer individuals are present in each age class. If fewer individuals exist in an age class, that class has more limited potential for influencing the future size of the population, either through its own reproduction or subsequent survival. This general pattern was also reflected by LTRE contributions from fertility and survival (Fig. 4). Fertility may have exhibited a graded response, reflecting both phenotypic plasticity and environmental scope. The nonlawn population exhibited the highest increase in growth rate under the experimental treatment, roughly twice that of the lawn population on a per-year basis (Table 2). The nonlawn population also exhibited the greatest contribution of fertility to increase in $\lambda$ (Table 3 ), primarily through the response of breeding females of the first age class (Fig. 3).

Numerous studies of vertebrate populations have been conducted to investigate the population-level response to natural or experimental perturbations in the environment. For example, Boutin (1990) reviewed studies that investigated population-level responses of terrestrial vertebrates to food supplementation. Fifty out of $66(75.8 \%)$ studies he reviewed reported an increase in size or growth rate of the study population in response to supplemented food. However, most studies reviewed by Boutin (1990) either did not provide demographic mechanisms for observed changes in population growth rate or assumed that variables with large responses to the treatment contributed most to observed changes in population growth rate, an assumption that may not hold (Caswell 1989a). In vertebrates, demographic mechanisms of population dynamics remain poorly understood (Dobson 1995), and LTRE analysis of experimental data, such as those reviewed by Boutin (1990), can substantially contribute to our understanding of the dynamics and regulation of biological populations. LTRE analysis has much to offer in discerning the demographic mechanism of population-level re- 
sponses to naturally occurring or experimentally induced changes in the environment.

One of the most promising uses of prospective methods is in formulating conservation or management plans (e.g., Crouse et al. 1987, Crowder et al. 1994, Doak et al. 1994, Heppel et al. 1994, Silvertown et al. 1995, Mills et al. 1998, de Kroon et al. 2000). For example, Crouse et al. (1987) used elasticities to demonstrate that growth rates of populations of loggerhead sea turtles (Caretta caretta) were relatively insensitive to changes in fertility. They concluded that increasing survival of juvenile turtles at sea would be more beneficial than protecting eggs as a conservation strategy. Our results, as well as those of other LTRE studies (Caswell 1989a, Levin et al. 1996), demonstrate that life history variables with high elasticities can be resistant to change. Thus, potentially influential variables also must be capable of response to natural or experimentally induced changes in the environment, and caution must be exercised in using elasticities alone in conservation planning (also see Green and Hirons 1991, Shea and Kelly 1998, de Kroon et al. 2000, Heppell et al. 2000b). The challenge for the future is to combine the expected magnitude of change with sensitivities or elasticities in formulating management plans.

\section{ACKNOWLEDGMENTS}

Funding for the field work was provided by the National Science Foundation and National Institutes of Health to D. F. Balph and A. W. Stokes. Manuscript preparation was supported in part by a Merriwether Fellowship and a Graduate Student Research Award of Auburn University to M. K. Oli. We thank Hal Caswell, Helen Alexander, Edward Heske, Selina Heppell, Jan Murie, the mammal group at the University of Kansas, and an anonymous reviewer for thoughtful comments on an earlier draft of the manuscript.

\section{Literature Cited}

Arcese, P., and J. N. M. Smith. 1988. Effects of population density and supplemental food on reproduction in song sparrows. Journal of Animal Ecology 57:119-136.

Birch, L. C. 1953. Experimental background to the study of the distribution and abundance of insects. Ecology 34:698711 .

Boutin, S. 1990. Food supplementation experiments with terrestrial vertebrates: patterns, problems, and the future. Canadian Journal of Zoology 68:203-220.

Brault, S., and H. Caswell. 1993. Pod-specific demography of killer whales (Orcinus orca). Ecology 74:1444-1454.

Caswell, H. 1989a. The analysis of life table response experiments. I. Decomposition of treatment effects on population growth rate. Ecological Modelling 46:221-237.

Caswell, H. 1989b. Matrix population models: construction, analysis, and interpretation. Sinauer, Sunderland, Massachusetts, USA.

Caswell, H. 1997. Matrix methods for population analysis. Pages 20-58 in S. Tuljapurkar and H. Caswell, editors. Structured population models in marine, terrestrial, and freshwater systems. Chapman \& Hall, New York, New York, USA.

Caswell, H. 2000. Prospective and retrospective perturbation analyses: their roles in conservation biology. Ecology 81: 619-627

Caswell, H., R. J. Naiman, and R. Morin. 1984. Evaluating the consequences of reproduction in complex salmonid life cycles. Aquaculture 43:123-134.

Cole, F. R., and G. O. Batzli. 1978. Influence of supplemental feeding on a vole population. Journal of Mammalogy 59: $809-819$

Cole, L. 1954. The population consequences of life-history phenomena. Quarterly Review of Biology 29:103-137.

Crouse, D. T., L. B. Crowder, and H. Caswell. 1987. A stagebased population model for loggerhead sea turtles and implications for conservation. Ecology 68:1412-1423.

Crowder, L. B., D. T. Crouse, S. S. Heppell, and T. H. Martin. 1994. Predicting the impact of turtle excluder devices on loggerhead sea turtle populations. Ecological Applications 4:437-445.

de Kroon, H., A. Plaisier, J. van Groenendael, and H. Caswell. 1986. Elasticity: the relative contribution of demographic parameters to population growth rate. Ecology 67:14271431.

de Kroon, H., J. van Groenendael, and J. Ehrlén. 2000. Elasticities: a review of methods and model limitations. Ecology 81:607-618.

Doak, D., P. Kareiva, and B. Klepetka. 1994. Modeling population viability for the desert tortoise in the western Mojave desert. Ecological Applications 4:446-460.

Dobson, F. S. 1988. Limits of phenotypic plasticity in the life history of Columbian ground squirrels. Pages 193-210 in M. S. Boyce, editor. Evolution of life histories in mammals. Yale University Press, New Haven, Connecticut, USA.

Dobson, F. S. 1995. Regulation of population size: evidence from Columbian ground squirrels. Oecologia 102:44-51.

Dobson, F. S., and G. R. Michener. 1995. Maternal traits and reproduction in Richardson's ground squirrels. Ecology 76: $851-862$.

Dobson, F. S., and J. O. Murie. 1987. Interpretation of intraspecific life history patterns: evidence from Columbian ground squirrels. American Naturalist 129:382-397.

Ehrlèn, J., and J. van Groenendael. 1998. Direct perturbation analysis for better conservation. Conservation Biology 12: 470-474.

Green, R. E., and G. J. M. Hirons. 1991. The relevance of population studies to the conservation of threatened birds. Pages. 594-633 in C. M. Perrins, J. D. Lebreton, and G. J. M. Hirons, editors. Bird population studies: relevance to conservation and management. Oxford University Press, Oxford, UK.

Guyer, C. 1988. Food supplementation in a tropical mainland anole, Norops humilis: effects on individuals. Ecology 69: 350-361.

Heppell, S. S., H. Caswell, and L. B. Crowder. 2000b. Life histories and elasticity patterns: perturbation analysis for species with minimal demographic data. Ecology 81:654665.

Heppell, S., C. Pfister, and H. de Kroon. 2000a. Elasticity analysis in population biology: methods and applications. Ecology 81:605-606.

Heppell, S. S., J. R. Walters, and L. B. Crowder. 1994. Evaluating management alternatives for Red-cockaded Woodpeckers: a modeling approach. Journal of Wildlife Management 58:479-487.

Horvitz, C., D. W. Schemske, and H. Caswell. 1997. The relative "importance" of life-history stages to population growth: prospective and retrospective analyses. Pages 247271 in S. Tuljapurkar and H. Caswell, editors. Structured population models in marine, terrestrial, and freshwater systems. Chapman \& Hall, New York, New York, USA.

Jansson, C., J. Ekman, and A. Von Bromssen. 1981. Winter mortality and food supply in tits, Parus spp. Oikos 37:313322 .

Jouventin, P., B. Lequette, and F. S. Dobson. 1999. Age- 
related mate choice in the wandering albatross. Animal Behaviour 57:1099-1106.

Knopf, F. L., and D. F. Balph. 1977. Annual periodicity of Uinta ground squirrels. Southwestern Naturalist 22:213224.

Krebs, C. J. 1996. Population cycles revisited. Journal of Mammalogy 77:8-24.

Krebs, C. J., S. Boutin, R. Boonstra, A. R. E. Sinclair, J. N. M. Smith, M. R. T. Dale, K. Martin, and R. Turkington. 1995. Impact of food and predation on the snowshoe hare cycle. Science 269:1112-1115.

Lenski, R. E., and P. M. Service. 1982. The statistical analysis of population growth rates calculated from schedules of survivorship and fecundity. Ecology 63:655-662.

Levin, L. A., H. Caswell, T. Bridges, D. Cabera, G. Plaia, and C. DiBacco. 1996. Demographic responses of estuarine polychaetes to sewage, algal, and hydrocarbon contaminants. Ecological Applications 6:1295-1313.

Lewontin, R. C. 1965. Selection for colonizing ability. Pages 79-94 in H. G. Baker and G. L. Stebins, editors. The genetics of colonizing species. Academic Press, New York, New York, USA.

Marcström, V., R. Kenward, and E. Engren. 1988. The impact of predation on boreal tetraonids during vole cycles: an experimental study. Journal of Animal Ecology 57:859877.

McPeek, M. A., and S. Kalisz. 1993. Population sampling and bootstrapping in complex designs: demographic analysis. Pages 232-252 in S. M. Scheiner and J. Gurevitch, editors. Design and analysis of ecological experiments. Chapman \& Hall, New York, New York, USA.
Mills, L. S., D. F. Doak, and M. J. Wisdom. 1998. Reliability of conservation actions based on elasticity analysis of matrix models. Conservation Biology 13:815-829.

Oli, M. K. 1999. Demographic mechanisms of population dynamics in mammals. Dissertation. Auburn University, Auburn, Alabama, USA.

Oli, M. K., and F. S. Dobson. 1999. Population cycles in small mammals: the role of age at sexual maturity. Oikos 86:557-565.

Oli, M. K., and B. Zinner. 2001. Partial life-cycle analysis: a model for birth-pulse populations. Ecology 82:00-00.

Rao, T. R., and S. S. S. Sharma. 1986. Demographic parameters of Brachiomus patulus Muller (Rotifera) exposed to sublethal DDT concentrations at low and high food levels. Hydrobiologica 139:193-200.

Shea, K., and D. Kelly. 1998. Estimating biocontrol agent impact with matrix models: Carduus nutans in New Zealand. Ecological Applications 8:824-832.

Silvertown, J., M. Franco, and E. Menges. 1995. Interpretation of elasticity matrices as an aid to the management of plant populations for conservation. Conservation Biology 10:591-597.

Slade, N. A., and D. F. Balph. 1974. Population ecology of Uinta ground squirrels. Ecology 55:989-1003.

Taitt, M. J., and C. J. Krebs. 1983. Predation, cover, and food manipulations during a spring decline of Microtus townsendii. Journal of Animal Ecology 52:837-848.

Tkadlec, E., and J. Zejda. 1998. Small rodent population fluctuations: the effects of age structure and seasonality. Evolutionary Ecology 12:191-210. 